\title{
On a Hermaphrodite Specimen of Amphioxus with Notes on Experiments in Rearing Amphioxus.
}

\author{
By \\ J. H. Orton, D.Sc., \\ Naturalist at the Plymouth Laboratory. \\ With Fignres 1-5 in the Text.
}

A SPECIMEN of Amphioxus lanceolatus containing both sperm and eggs was observed in June this year whilst experiments were being conducted on obtaining the larvæ of this animal. The individual in which this phenomenon was observed is predominantly male, and was actually seen to discharge a large amount of living spermatozoa, but of the forty-three
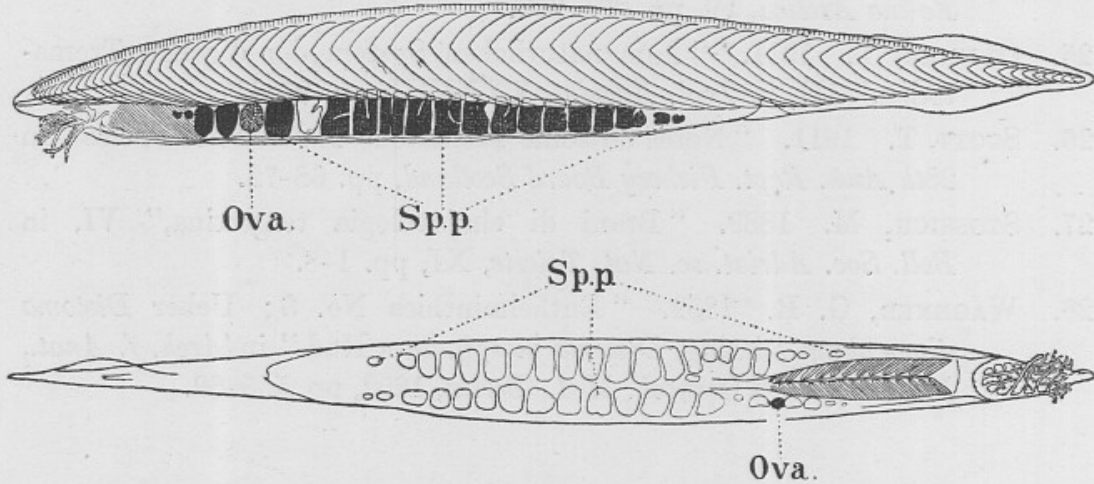

FIGS. 1 and 2.- *Views of a hermaphrodite specimen of Amphioxus from the left side and the ventral region respectively. Ova are present in one gonadial pouch only, while all the remaining pouches contain sperm. (Drawn from the whole animal stained in Delafield's hæmatoxylin and cleared in cedar-wood oil, $\times$ about $2 \frac{1}{2}$.)

Sp.p. Gonadial pouches full of sperm.

large gonadial pouches present in the animal one only contains eggs and the remainder sperm. On the right side of the body are twenty-two welldeveloped gonadial pouches, two of which became nearly empty by the discharging of spermatozoa; the remainder were full of sperm when the animal was preserved. On the left are nineteen pouches full of sperm and one is nearly empty, but one pouch, the fifth from the anterior end,

* I am indebted to Mrs. Orton for the drawings for Figs. 1 and 2, and for assistance with that for Fig. 3 ; and also to Mr. E. Ford for the lettering of the Figures. 
is full of eggs (see Figs. 1 and 2). The relation of the pouches on the right side to those on the left appears (as may be seen from Fig. 2) to be normal. The smaller pouches have been reduced somewhat in size from the loss of sperm referred to above. A few other rudimentary microscopic pouches are present in the posterior region of the body.

FIG. 3.

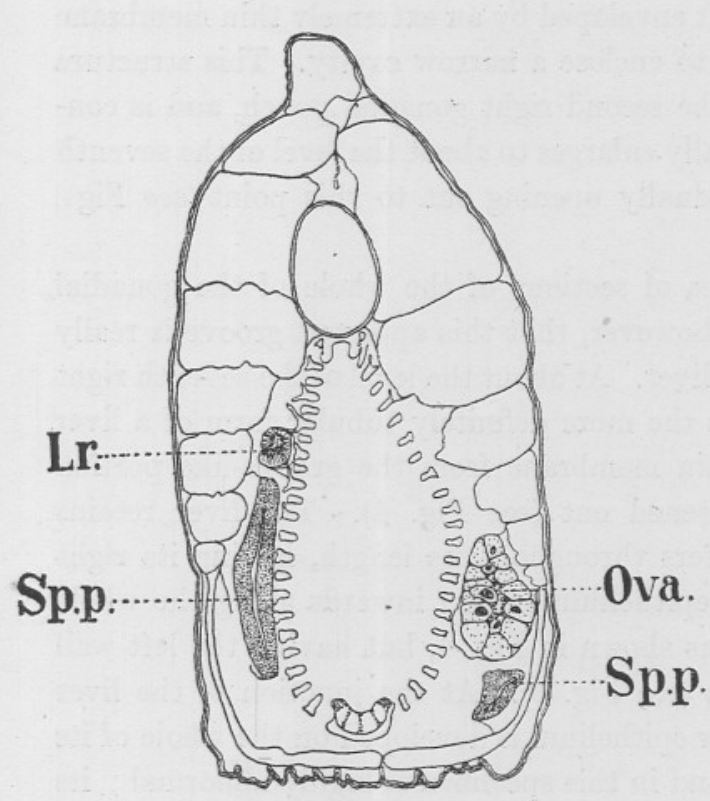

FIG. 4.

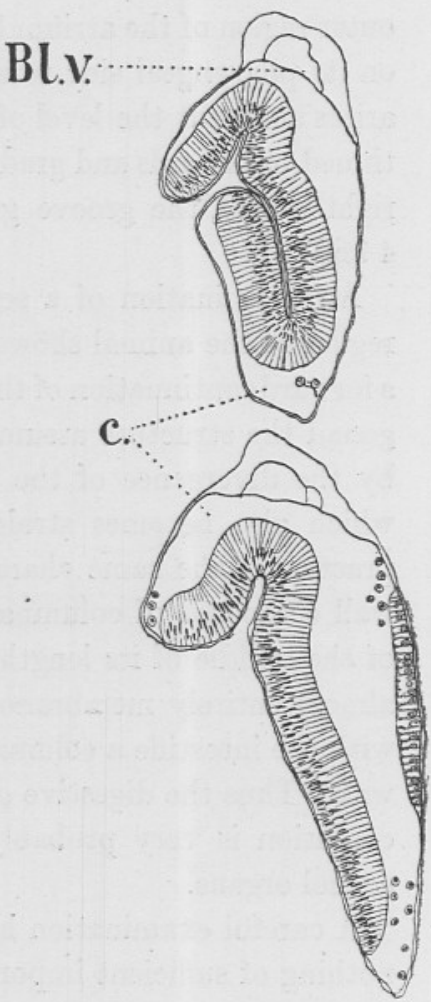

FIG. 5.

FiG. 3.-Transverse section through a hermaphrodite specimen of Amphioxus lanceolatus showing gonadial pouches with sperm or ova and the anterior end of the abnormal liver. Ova are present in one pouch only.

Sp.p. Gonadial pouches filled with sperm.

Lr. Anterior prolongation of liver.

FrG. 4.-Transverse section of liver at the level of the sixth right gonadial pouch (semidiagrammatic).

Bl.v. Blood vessel in coelomic space surrounding the liver.

C. Cavity of liyer.

FIG. 5.-Transverse section of liver at the level of the thirteenth right gonadial pouch (semi-diagrammatic).

In transverse sections the gonadial pouch bearing eggs is seen to have the primary and secondary cavities normally shown by the female 
gonads (see Fig. 3), and the invaginated form of the pouch described by Legros* is also well shown in some sections (but is not shown in Fig. 3). Thus the structure of this pouch is of the normal female plan.

The transverse section shown in Fig. 3 shows also an abnormal feature of much interest. On the right side (the reader's left) in the dorsal region of the atrial cavity is a structure resembling a groove opening on to the outer region of the atrium but enveloped by an extremely thin membrane on its pharyngeal side so as to enclose a narrow cavity. This structure arises at about the level of the second right gonadial pouch, and is continued backwards and gradually enlarges to about the level of the seventh right gonad, the groove gradually opening out to this point (see Fig. 4 and 5).

An examination of a series of sections of the whole of the gonadial region of the animal shows, however, that this apparent groove is really a forward continuation of the liver. At about the level of the seventh right gonad the structure assumes the more definitely tubular form of a liver by the divergence of the thin membrane from the groove-like portion which also becomes straightened out (see Fig. 4). The liver retains practically the same characters throughout its length, having its right wall composed of columnar epithelium tucked inwards along the whole of the middle of its length, as shown in Fig. 4, but having the left wall almost entirely membranous (see Fig. 5). At the junction of the liver with the intestine a columnar epithelium is developed on the whole of its wall. Thus the digestive gland in this specimen is highly abnormal ; its condition is very probably correlated with the abnormal state of the sexual organs.

A careful examination has been made of the tissues for parasites, but nothing of sufficient importance has so far been detected to confirm the suggestion that the hermaphroditism may be due to the influence of parasites. A fair number of small nucleated spherical bodies are present in the cavity of the liver, and bodies are present in some of the abnormal intuckings of the intestinal wall which may be parasites, but the methods of staining employed up to the present have certainly not disclosed such an extensive invasion of foreign bodies in the tissues as perhaps one might expect to find in an animal whose sex is abnormally changed by an infection of parasites.

The occurrence of hermaphrodite specimens of Amphioxus has been recorded previously on only two occasions so far as I know. In 1876

* M. Legros, "Sur la Morphologie des Glandes sexuelles de l'A mphioxus lanceolatus," Comptes-Rendus du Troisième Congrès Internationale de Zoologie, Leyden,1895. 
Langerhans stated* that he had detected the tails of spermatozoa among young ovarian ova of Amphioxus, and recently in 1912 Goodrich $\dagger$ described a more definitely hermaphrodite specimen from Naples which closely resembles the one obtained here at Plymouth in having only one gonadial pouch producing eggs - the ninth on the left side-but with the remaining forty-nine pouches full of spermatozoa.

Goodrich has already pointed out that hermaphroditism would appear to be a rare phenomenon in Amphioxus since large numbers have been and are being carefully examined. It occurred to me, however, that possibly the hermaphroditism might be more common in Amphioxus than would appear to be in the case, for after the discharge of the gonadial products the gonadial pouches contract into a very small compass, and presumably a fresh set of gonadial products are formed subsequently. Thus it would be possible for a given individual Amphioxus to have two different sets of gonads, first of one sex and afterwards of the other. Moreover, such a change would probably not be detected unless a number of Amphioxus were reared in captivity from the young to the adult stage. In this way the chance observations referred to above of two males each with one egg-bearing pouch may possibly indicate an unsuspected change of sex in the life-history of the animal. If such a change were to occur the occurrence of egg-bearing pouches in a male might be an expression of a precocious development of female characteristics. A further indication that a change of sex would be in the direction of male to female lies in the fact that the hermaphrodite forms are both of medium size: Goodrich's specimen being about $4.7 \mathrm{cms}$. long, and mine measured $4.4 \mathrm{cms}$. in cedar-wood oil. It is very probable that the animals become mature for the first time at about this size.

On the view, however, that there is a sex-change in Amphioxus one would expect all the young individuals to be of the same sex, but the researches of three different investigators, namely, Legros (l.c.), Neidert and Leiber, $\ddagger$ and Zarnik, $\S$ show that both male and female gonads have been traced in very small individuals. Hence it seems certain that there cannot be any total sex-change in Amphioxus; but there still remains

* P. Langerhans, Archiv f. Mikr. Anat., Bd. XII, 1876, p. 326. 1912.

$\dagger$ E. S. Goodrich, "A Case of Hermaphroditism in Amphioxus," Anat. Anz., 42 Bd,

‡ L. Neidert u. A. Leiber, " Über Bau und Entwicklung der Weiblichen Geschlechtsorgane des Amphioxus," Zool. Jahrb., Bd. XVIII, 1903.

$\S$ B. Zarnik, "Uber die Geschlechtsorgane von Amphioxus," Zool. Jahrb. Abt. Anat., Bd. XXI, 1905. 
the possible, but hardly probable, occurrence of a sex-change in only some individuals.

It would therefore appear that these occasional hermaphrodites in Amphioxus must remain for the present unexplained like the similar and not uncommon phenomena among many fishes.* The abnormality of the liver and the intestine as well as that of the sexual organs points, however, to some deep-seated disorganisation in the economy of the animal, the cause of which I have not been able to detect.

\section{NOTES ON EXPERIMENTS ON REARING AMPHIOXUS.}

A few experiments were carried out this summer with the object of obtaining the larvæ of Amphioxus. As two of the experiments were successful, and as the larvæ of Amphioxus have apparently not been obtained at Plymouth before, these notes may be useful to future workers.

Larvæ of Amphioxus were obtained on two occasions on June 10th and June 15th by merely isolating a number of adult males and females in a small glass bowl. The adult specimens were examined under a microscope when brought in and a few mature males put into bowls in company with mature females. It is possible to distinguish the adult sexes in the living condition, and indeed the hermaphrodite specimen described in the preceding pages was identified as such while alive. It was found advantageous to feed the Amphioxus on a fairly thick culture of the diatom Nitzschia which the animals ingest in great numbers. By gorging themselves with this food the Amphioxus are probably able to extrude eggs or sperm more easily than when they are empty.

Spawning apparently occurs usually overnight, as gastrulæ were cbtained in both experiments about midday. It is not easy to calculate the time of spawning from the known age of gastrulæ reared at Naples, since the rate of development of larvæ at Plymouth is undoubtedly slower than at Naples, as was shown by subsequent observations. Since, however, gastrulæ were obtained about noon it seems likely that spawning had occurred sometime about midnight. In this respect it is interesting to observe that the hermaphrodite specimen just described was

* With regard to the occasional hermaphrodites among fishes it may be remarked that it is highly important to know the size and also the age of specimens-which are usually omitted from descriptions-if the data are to be useful for investigating the life-history of the fish. 
observed to spawn during the day, ${ }^{*}$ but it is probable that this spawning may have been abnormal and induced by the animal having jumped out of a bowl and remained dry on the bench for a little while.

In the second experiment in which fertilised eggs were obtained the embryos had reached the blastula and gastrula stages by 1.0 p.m. At 6.0 p.m. on the same day, June 15 th, the gastrulæ began to elongate, and by 9.0 p.m. two to three mesoblastic somites were developed and the larvæ were beginning to find their way out of their fertilization membranes. On June 16th at 2.5 p.m. the larvæ had developed six to eight pairs of mesoblastic somites and the head cavities. On the 17 th at 2.30 p.m. the larvæ reached a stage similar to Hatschek's Fig. $64, \uparrow$ in which the club-shaped gland is present. At Naples this stage is reached at an age of about 36 hours, whereas the Plymouth embryos only reached the corresponding stage at an age of about 60 hours. During subsequent days the larvæ increased a little in length and were observed to be feeding, but even on the 30th of the month when the larvæ were a fortnight old only the first few gill-slits had appeared, and shortly afterwards it was unfortunately necessary to abandon the larvæ.

In preserving batches of larvæ it was observed that the individual of the latter stages became stuck to the bottom of the vessel in the head region. This circumstance seems to point to the possibility of the clubshaped gland pouring out some secretion to the exterior, since this gland is the only organ developed at this stage ; and since moreover, according to Willey, $\ddagger$ " this stage of the larval development appears to be of the nature of a resting phase, during which the larvæ accumulates energy for future growth," it may be that a secretion of the club-shaped gland serves to attach the larva temporarily to objects during this resting stage, or to suspend the larva in the water (see Willey, l.c., p. 130). These are, however, merely suggestions, which nevertheless might well repay further investigation by naturalists who may have the opportunity of doing so.

It may further be noted that the opening of the club-shaped gland is on the left side; hence if a secretion of this gland is used for attaching the larva temporarily to objects, then the larva would be able to feed only from the right side of the body. As is well known, the first formed gillslits do develop on the right side of the body and afterwards shift over

\footnotetext{
* The actual time was not recorded, but it was some time between 11 a.m. and 4.30 p.m.

$\dagger$ B. Hatschek, "Entwicklung des Amphioxus," Arb. Zool. Inst. Wien., 1881, Vol. IV.

‡ A. Willey, Amphioxus and the Ancestry of the Vertebrates, 1894, p. 172.
} 
to the left after the disappearance of the club-shaped gland. It is therefore possible that the larval asymmetry of Amphioxus may be correlated with the function of the club-shaped gland, and if the suggestion here made that this gland may secrete a substance for attaching the larva temporarily to objects is found to be a fact, a simple explanation similar to that put forward by Korscheldt and Heider is offered of the curious asymmetry in the early larval development of this interesting animal.

\section{SUMMARY.}

A hermaphrodite specimen of Amphioxus has been taken at Plymouth having one gonadial pouch filled with ova and the remaining pouches filled with sperm. This specimen closely resembles a similar one taken by Goodrich at Naples.

The liver and intestine of the Plymouth specimen are abnormal, but no parasites have been identified in the tissues to account for these abnormalities.

It is, moreover, improbable that there is any normal sex-change in Amphioxus, since three independent investigators have found very small specimens of both sexes, therefore no satisfactory explanation can be given of the occurrence of hermaphroditism in the specimen.

Amphioxus have been found to spawn in June, and larvæ have been obtained from the captive specimens.

It is suggested that the club-shaped gland may secrete a substance for attaching the larva of Amphioxus to objects, and that this function may be correlated with the asymmetry shown in the early development of the Amphioxus larva. 